\title{
A rede de desinformação e a saúde em risco: uma análise das fake news contidas em 'As 10 razões pelas quais você não deve vacinar seu filho'
}

\author{
The misinformation network and health at risk: an analysis of fake news \\ included in 'The 10 reasons why you shouldn't vaccinate your child'
}
La red de desinformación y la salud em riesgo: um análisis de noticias falsas presentadas em 'Las 10 razones por las que no debe vacunar a su hijo'

Carla Montuori Fernandes ${ }^{1, a}$

carla.montuori@docente.unip.br | https://orcid.org/0000-0002-7625-8070

Christina Montuori ${ }^{1, b}$

christina.montuori@docente.unip.br | https://orcid.org/o0o0-0003-1698-8239

\footnotetext{
${ }^{1}$ Universidade Paulista. São Paulo, SP, Brasil.

a Doutorado em Ciências Sociais pela Pontifícia Universidade Católica de São Paulo.

b Mestrado em Comunicação pela Universidade Paulista.
}

\section{Resumo}

Este artigo tem por objetivo contrapor o conjunto de argumentos em que se apoiaram as fake news contidas em 'As 10 razões pelas quais você não deve vacinar seu filho', divulgadas na página do Facebook Pensadores contra o sistema, com pesquisas científicas publicadas na literatura da área de vacinação e imunização. Pretende-se, ainda, apresentar dados que apontam o decréscimo dos indicadores de vacinação no Brasil e no mundo, estabelecendo possível associação dessa diminuição com o avanço das notícias falsas que têm sido propagadas no ambiente virtual. Observou-se ao longo da pesquisa que a nova ambiência midiática propiciou a expansão de informações falsas sobre vacinação, apoiadas em dados que parecem se estruturar em argumentos científicos, mas não resultam da aplicação de experimentações e de métodos seguros.

Palavras-chave: Saúde; Vacinação; Comunicação; Rede sociais; Fake news. 


\begin{abstract}
This article aims to counter the set of arguments which supported the fake news included in 'The 10 reasons why you should not vaccinate your child', published on the Facebook page Thinkers against the system, with scientific research published by literature on vaccination and immunization. It is also intended to present data that point out the decrease in vaccination indicators in Brazil and in the world, establishing a possible association between this reduction and the advance of false news that has been disseminated in the virtual environment. It was observed throughout the research that the new communication environment based on social media provided the expansion of false information about vaccination, supported by data that seem to be structured in scientific arguments, but do not result from neither clinical trials nor the use of safe methods.
\end{abstract}

Keywords: Health; Vaccination; Communication; Social networks; Fake News.

\title{
Resumen
}

Este artículo tiene como objetivo contra poner el conjunto de argumentos que respaldan lãs fake news presentadas em 'Las 10 razones por las que no debe vacunar a su hijo', publicadas em la página del Facebook Pensadores contra el sistema, com investigaciones científicas publicadas em la literatura médica del área de vacunación e inmunización. También se pretende presentar datos que apuntan la disminución de los indicadores de vacunación en Brasil y em el mundo, estableciendo una posible relación entre esa reducción y el avance de las noticias falsas que se han sido difundidas em el entorno virtual. Se observó a lo largo de la investigación que El nuevo entorno de los médios em el que se hace el uso de los médios sociales proporcionó la expansión de informaciones falsas sobre la vacunación, respaldadas por datos que parecen estar estructurados en argumentos científicos, pero que no resultan de la aplicación de experimentos y de métodos seguros.

Palabras clave: Salud, Vacunación, Comunicación, Redes sociales, Noticias falsas.

INFORMAÇÕES DO ARTIGO

\begin{abstract}
Contribuição dos autores:
Concepção e desenho do estudo: Carla Montuori Fernandes.

Aquisição, análise ou interpretação dos dados: Carla Montuori Fernandes e Christina Montuori.

Redação do manuscrito: Carla Montuori Fernandes e Christina Montuori.

Revisão crítica do conteúdo intelectual: Carla Montuori Fernandes.
\end{abstract}

Declaração de conflito de interesses: não há.

Fontes de financiamento: O projeto de pesquisa 'Meios e Mídia no contexto da pós-verdade' é financiado pela Universidade Paulista (Unip).

Agradecimentos/Contribuições adicionais: não há.

Histórico do artigo: submetido: 15 dez. 2019 | aceito: 06 abr. 2020 | publicado: 30 jun. 2020.

Apresentação anterior: não houve.

Licença CC BY-NC atribuição não comercial. Com essa licença é permitido acessar, baixar (download), copiar, imprimir, compartilhar, reutilizar e distribuir os artigos, desde que para uso não comercial e com a citação da fonte, conferindo os devidos créditos de autoria e menção à Reciis. Nesses casos, nenhuma permissão é necessária por parte dos autores ou dos editores. 


\section{Introdução}

O termo pós-verdade vem sendo incorporado nas discussões atuais, tendo em vista a crescente onda de falseamento e/ou distorção da realidade, diante de inúmeros fenômenos contemporâneos, entre os quais se destacam as fake news. The Oxford English Dictionary foi o primeiro a conceituar o termo pós-verdade no ano de $2016^{1}$, relacionando-o a um adjetivo que denota circunstâncias nas quais fatos objetivos e racionais têm menos influência para moldar a opinião pública do que apelos à emoção e às crenças pessoais.

Anthony Gooch² referenciou que a pós-verdade consiste na revitalização da verdade, na banalização da objetividade dos dados e na supremacia do discurso emotivo. Para o autor, o conceito de pós-verdade constitui um neologismo cada vez mais usado na compreensão de fenômenos relacionados à percepção de mundo e às novas circularidades de informações/opiniões.

Por não se tratar de um fenômeno novo, a pós-verdade já ocupava as discussões de Ralph Keyes, em 2004, quando da publicação do livro Dishonesty and Deception in Contemporary Life. Zarzalejos ${ }^{3}$ descreve a pós-verdade como arma política da desinformação e faz referência às "dezestratégias de manipulação", que Noam Chomsky elaborou ao referenciar o fenômeno, conferindo ênfase às técnicas para suavizar emotivamente as mensagens, com a intenção de ocasionar uma espécie de curto-circuito no senso crítico e analítico dos cidadãos.

No ambiente em que as crenças pessoais se sobrepõem à lógica e aos fatos, emergem novas formas de relação da mídia com a sociedade. O jornalismo tradicional tem perdido espaço diante da dinâmica veloz das redes sociais e das mídias alternativas, já que, em determinadas circunstâncias, um post no Facebook ou mesmo um tweet têm potencial de mobilizar de maneira significativa a opinião pública.

Esse novo espaço de interação se transformou em um terreno fértil para a proliferação de notícias falsas e/ou falsificadas. Informações equivocadas, enviesadas e conteúdos que alimentam uma rede de desinformação sempre estiveram presentes na dinâmica da vida social e se ampliaram com a consolidação dos meios de comunicação.

Para Delmazo e Valente 4 , a internet e as redes sociais são parte integrante do problema, já que: "As notícias falsas podem ser consideradas não apenas em termos da forma ou conteúdo da mensagem, mas também em termos de infraestruturas mediadoras, plataformas e culturas participativas que facilitam a sua circulação. Nesse sentido, o significado das notícias falsas não pode ser totalmente compreendido fora da sua circulação on-line".

Ortellado ${ }^{5}$ aponta que o Brasil é considerado um dos países com maior produção, circulação e consumo de notícias falsas do mundoi. Entre inúmeras informações falsas que circularam no ambiente virtual, deve-se destacar a paranoia conspiracionista em torno da vacinação, apoiada no movimento anti-vaxx. O movimento antivacinação (ou anti-vaxx) é representado por um grupo de indivíduos que se recusa a aderir a qualquer forma de imunização, devido à crença de que existe um complô arquitetado pela indústria farmacêutica com a anuência do Estado, cujo objetivo é ocultar supostos efeitos colaterais das vacinas sobre a população, como o aumento nos índices de crianças com autismo. Esse movimento ganhou espaço nas redes sociais após a divulgação de uma pesquisa, nunca comprovada, que relacionava as vacinas ao surgimento da doença.

O movimento se apoia em uma pesquisa com doze crianças publicada na revista The Lancet, em 1998, pelo ex-pesquisador britânico Andrew Wakefield, em que ele constata que quatro crianças se tornaram autistas após tomar a vacina tríplice viral, usada para prevenção do sarampo, rubéola e caxumba. O fato é que o movimento alcançou enorme repercussão e se transformou em um problema de saúde pública mundial, mesmo após a constatação de que o médico utilizou métodos questionáveis no desenvolvimento da pesquisa.

i Disponível em: https://portal.comunique-se.com.br/fake-news-podem-influenciar-eleicao-alerta-professor-da-usp/. Acesso em: 2019 set. 15. 
Posteriormente, inúmeras pesquisas foram publicadas para questionar o controvertido artigo, mas os efeitos já eram visíveis entre a população americana e europeia, como o aumento expressivo de casos de sarampo e rubéola em vários países. Isso acaba por promover inúmeros riscos de surtos de doenças já controladas, como tem ocorrido com o aumento de casos de sarampo no Brasil, em 2019

Nesse sentido, o artigo tem por objetivo confrontar, com dados e pesquisas científicas, os argumentos empregados nas fake news contidas em ‘As 10 razões pelas quais você não deve vacinar seu filho', que foram publicadas em 18 de setembro de 2016, na página do Facebook Pensadores contra o sistema e circulou nas redes sociais brasileiras. Pretende-se discutir em que medida as fake news se sustentam na dinâmica do espaço virtual e atuam na perspectiva de construir movimentos e argumentos contrários às campanhas de vacinação e ao processo de imunização, que possivelmente resultam no aumento de surtos de doenças no país e no mundo.

A Página Pensadores contra o sistema foi criada em 2015, trazendo na capa o slogan 'Liberte-se do sistema! Seja livre!'. A página possui 77 mil seguidores e promove discussões de cunho político e social. A lista com os dez motivos para não vacinar seu filho foi eleita como objeto da pesquisa porque abarca pontos que foram disseminados em inúmeras outras fake news que viralizaram sobre o tema, levando o Ministério da Saúde a emitir um comunicado para que notícia falsa não fosse compartilhada ${ }^{i i i}$. Pesquisa recente aplicada em mais de dois mil entrevistados, nas cinco regiões do Brasil, constatou que $67 \%$ da amostra acreditavam em pelo menos uma das dez afirmações falsas que circularam nas redes sociais sobre vacinação $0^{\text {iv }}$.

$\mathrm{O}$ artigo traz uma perspectiva bibliográfica e descritiva, realizada por meio do levantamento de artigos e documentos proveniente de pesquisas consolidadas na área de vacinação e imunização, cujos resultados são apresentados e discutidos ao longo do texto.

\section{Epidemia de desinformação: uma breve trajetória dos movimentos antivacinação}

No Brasil, a primeira campanha de vacinação foi realizada em 1804, para conter um surto de varíola. Exatamente 100 anos depois teve início o primeiro questionamento contra a prevenção da doença, no movimento identificado como Revolta da Vacina (1904). Iniciado no Rio de Janeiro, na época capital do país, o movimento teve como estopim uma medida de imunização instaurada de maneira compulsória pelo Diretor Geral da Saúde Pública, Oswaldo Cruz.

A Revolta da Vacina teve como antecedente o contexto mundial da Segunda Revolução Industrial, momento em que o Brasil passava por algumas mudanças decorrentes dessas transformações. A cidade do Rio de Janeiro, que ainda apresentava características coloniais, entre as quais diversos surtos de doenças, sofreu uma política de remodelação urbana para atrair investimentos e turistas internacionais ${ }^{6}$. Para acelerar o processo, o sanitarista Oswaldo Cruz iniciou uma campanha para erradicação da febre amarela, que ficou conhecida como 'ditadura sanitária'. A campanha, que se resguardava em leis de exceção, permitia que autoridades invadissem, vistoriassem, fiscalizassem e demolissem casas e construções.

Os impactos da campanha contra a febre amarela culminaram com forte agitação popular no momento em que se estabeleceu a obrigatoriedade da vacina antivariólica. Apoiando-se no fato de a vacinação ser

\footnotetext{
ii Disponível em: http://saude.gov.br/noticias/agencia-saude/45750-cresce-18-numero-de-casos-de-sarampo-no-brasil. Acesso em: 2019 set. 15 .

iii Ministério da Saúde (BR). Olá! Não compartilhe essa notícia, ela é falsa! O texto que circula nas redes sociais, sobre as 10 razões pelas quais não deveria vacinar seu filho é cheio de inverdades e com informações sem fundamentação científica [Internet]. Brasília, DF: O Ministério; 2019 [acesso em 2020 mar. 02]. Disponível em: https://bit.ly/2Y7PRXC.

iv A pesquisa foi feita pela sociedade médica em parceria com a organização não governamental Avaaz. Os questionários foram aplicados pelo Ibope entre 19 e 22 de setembro de 2019.
} 
compulsória, os políticos de oposição instigaram o movimento, que também contou com a adesão da imprensa, que, além de conceder espaço nos jornais para figuras públicas contrárias à lei da vacina, colocava em dúvida a segurança da imunização, chamando-a de injeção de veneno. Para Sevcenko ${ }^{6}$, a memória traumática da campanha da febre amarela, aliada à falta de informação pública, fez com que a população passasse a reagir com resistência à vacinação contra a varíola. Nesse contexto, os políticos de oposição e a mídia foram os precursores do primeiro movimento de desinformação sobre uma campanha de vacinação no Brasil.

Sempre acompanhada de polêmica, a vacinação acumula defensores no âmbito da saúde coletiva em contraposição aos adversários que refutam benefícios proporcionados por ela. Porém, apesar de revoltas e disputas judiciais, cada vez mais indivíduos, seja de forma espontânea ou obrigados pelo Estado, se vacinam contra as doenças infecto-contagiosas. Ao longo da sua história, não há como negar que a vacina, entre os instrumentos de saúde pública, é responsável pelo controle de uma série de doenças que avassalariam países, pois é grande a mobilidade das pessoas propiciada pelo avanço nos meios de transporte, pela intensificação de viagens e pela transição numerosa que ocorre entre os continentes7.

O século XX, mais precisamente, a sua segunda metade, caracterizou-se expressivamente pela utilização de imunobiológicos no Brasil, impulsionados pelo sucesso da Campanha Mundial de Erradicação da Varíola e pelos avanços no desenvolvimento e produção das vacinas, como aquelas contra a poliomielite e, mais adiante, na década de 1990, sua erradicação nas Américas; a intensificação das campanhas vacinais; o Programa Ampliado de Imunizações (PAI) proposto pela Organização Mundial da Saúde (OMS) em 1974; e o aparecimento dos programas nacionais de vacinação, para citar importantes referências, ${ }^{7,8}$.

Nisso, os últimos trinta anos do século XX foram expressivos para a implementação de políticas de imunizações nacional, com os últimos registros de casos de varíola em 1971, a implantação de dias nacionais de vacinação, a partir de 1980, e a erradicação da poliomielite, em 1992. Destacaram-se, nessa época, a criação da Superintendência de Campanhas de Saúde (Sucam), em 1970; em 1971, a proposição de um Plano Nacional de Controle da Poliomielite, como primeira tentativa organizada para controle da doença no país e o início das atividades da Central de Medicamentos (Ceme), apoiando inicialmente a produção de vacinas e medicamentos; a institucionalização do Programa Nacional de Imunizações (PNI) e do Programa Nacional de Profilaxia da Raiva, em 1973; a aprovação do Programa Nacional de Combate à Meningite, em função da epidemia de meningite meningocócica, em 1974; e a instituição do Sistema Nacional de Vigilância Epidemiológica e Imunizações, incluindo a formalização do PNI e o estabelecimento das normas técnicas relativas ao seu funcionamento, em 1975.

Sobressaíram-se ainda a revitalização da Fundação Oswaldo Cruz (Fiocruz), a partir da segunda metade da década de 1970; o surgimento do Instituto de Tecnologia em Imunobiológicos - Bio-Manguinhos enquanto unidade integrante do Complexo Fiocruz, em 1976; a instituição do primeiro calendário básico de vacinação, com imunizações obrigatórias para os menores de um ano (contra tuberculose, poliomielite, sarampo, difteria, tétano e coqueluche), em 1977; em 1981, a criação do Instituto Nacional de Controle de Qualidade em Saúde (INCQS), na Fiocruz, que representou o fortalecimento desse processo no país, com responsabilidade de controlar produtos imunobiológicos disponíveis no mercado; o lançamento, pela Fiocruz, do primeiro lote da vacina brasileira contra o sarampo; a instituição do Programa de Autossuficiência Nacional de Imunobiológicos (Pasni), voltado para o suprimento da demanda nacional de vacinas e soros, em 1985; e a instituição do Sistema Único de Saúde (SUS), em 1988, com a promulgação da Constituição Federal, que colocou o promover da saúde como direito fundamental de cidadania, cabendo ao Estado a obrigação de garanti-lo ${ }^{7,8}$.

A década de 1990 foi marcada por implementações e ampliações da vacinação contra a hepatite B, sarampo, febre amarela, tétano, vacina tríplice viral (sarampo, rubéola e caxumba) - inicialmente em São Paulo, para posteriormente ser implementada gradualmente na rotina dos serviços de saúde para crianças 
de um ano de idade. Em 1999, iniciou-se a realização das campanhas nacionais de vacinação contra a gripe para a população a partir dos 65 anos, abrangendo proteção não somente para influenza, mas também para pneumonia pneumocócica e tétano ${ }^{8}$.

Nos anos 2000 foi a vez da confirmação do último caso autóctone de sarampo no país e a conclusão da estratégia nacional da vacina tríplice viral, por meio da realização de campanhas de vacinação iniciadas em 1992, resultando na redução da circulação do vírus da rubéola. Também, iniciou-se a implantação de um sistema de vigilância da influenza em âmbito nacional. Em 2002, o PNI ofertava 44 produtos imunobiológicos, sendo eles: 14 tipos de vacinas e dois tipos de soro heterólogo em postos de vacinação; 13 tipos de vacina e quatro tipos de imunoglobulina nos Centros de Referência para Imunobiológicos Especiais (Crie), para atender pessoas em situação de contraindicação para receber as vacinas existentes na rede de serviços, iniciados em 1993; e 14 tipos de soro heterólogo em unidades hospitalares e de pronto atendimento ${ }^{8}$.

Em 2010, o Ministério da Saúde apresentou relatório pleiteando a certificação da eliminação do sarampo e apontando as recomendações, os compromissos e os encaminhamentos relativos à eliminação da transmissão do vírus da rubéola, com vistas à certificação regional em 2012. O relatório registrou o resultado do trabalho desenvolvido no país, com foco em vigilância epidemiológica, vigilância laboratorial e imunização. A inclusão da vacina contra a varicela no Calendário de Vacinação da Criança, substituindo a vacina tríplice viral pela vacina combinada tetraviral (sarampo, caxumba, rubéola e varicela), para a população de um ano de idade, e a inclusão de pessoas portadoras de doenças crônicas não transmissíveis e outras condições especiais, bem como as puérperas até 45 dias após o parto, na Campanha Nacional de Vacinação contra Influenza, encerram $2013^{8}$.

Em 2019, o Ministério da Saúde, pela primeira vez desde 2012, quando passou a vigorar a Lei de Acesso à Informação, publicou um Boletim Epidemiológico reunindo as principais doenças que atingiram a população brasileira, nos últimos 16 anos. Dentro deste cenário, entre avanços e incorporações tecnológicas ocorridos de 2003 a 2019, mantiveram-se velhos desafios, como o aumento do número de casos de malária, de hanseníase, bem como a reintrodução da circulação do vírus do sarampo, após certificação da eliminação conferida para o país, em 2016, pela Organização Pan-Americana da Saúde (OPA), além dos registros entre 2014 e 2019, da febre amarela na Região Extra-Amazônica, como Centro-Oeste, Sudeste e Sul, além da Bahia ${ }^{9}$.

O aumento dos casos de doenças infecciosas está em parte associado ao movimento antivacinação, que ressurge no país, após mais de um século da Revolta da Vacina (1904). Tais movimentos são pautados em conteúdos de informações incorretas, seja por meio da crença de que tratamentos alternativos de saúde, como a homeopatia, a medicina antroposófica e uma alimentação saudável, são suficientes para manter a saúde das crianças. Apoiados na facilidade de manipulação das mídias sociais, inúmeros perfis e páginas fraudulentas interagem no ambiente virtual, disseminando conteúdos enganosos.

O efeito da retórica alarmista foi sentido na Europa com os recentes surtos de sarampo em vários países, incorrendo em 35 óbitos pela doença em locais como Romênia, Portugal, Alemanha e Itália ${ }^{10}$. A mídia estadunidense tem associado o maior surto de sarampo, que ocorreu no ano de $2014^{11}$, aos impactos dos movimentos antivacinação, havendo naquele ano 667 casos da doença, dos quais 383 ocorreram em comunidades religiosas e não vacinadas no estado de Ohio ${ }^{12}$. No Brasil, os grupos que compartilham conteúdos falsos em torno do movimento antivacinação têm apresentado aumento expressivo. Como exemplo, o Ministério da Saúde registrou mais de 100 notícias falsas, sendo que a vacinas se destacam como um dos principais temas ${ }^{\mathrm{v}}$.

v Ministério da Saúde (BR). 12 mil dúvidas em um ano de combate às fake news [Internet]. Brasília, DF: O Ministério; 2019 [citado em 2019 set. 20]. Disponível em: https://bit.ly/3bGuMaL. 


\section{O ambiente de desinformação nas redes sociais}

O desenvolvimento da cibercultura possibilitou novas interações socioculturais, concebendo costumes e práticas sociais mediadas pelas tecnologias da informação e da comunicação em rede. O atual cenário sociotécnico aumentou em larga escala o volume e a variedade de informações, potencializando outras lógicas de valorização e participação dos indivíduos que se tornam produtores de conteúdos no ciberespaço. Os conceitos de cibercultura e ciberespaço fundamentam a obra de Pierre Levy ${ }^{13} \mathrm{e}$ dele derivam suas principais reflexões. Assim: "o termo [ciberespaço] especifica não apenas a infraestrutura material da comunicação digital, mas também o universo oceânico de informação que ela abriga, assim como os seres humanos que navegam e alimentam esse universo. Quanto ao neologismo 'cibercultura', especifica aqui o conjunto de técnicas (materiais e intelectuais), de práticas, de atitudes, de modos de pensamento e de valores que se desenvolvem juntamente com o crescimento do ciberespaço".

Lévy $^{13}$ aponta que as tecnologias digitais possibilitaram novas formas comunicação e sociabilidade, bem como novos mercados de informação e conhecimento. A arquitetura de rede moldou uma nova estrutura de comunicação, que permitiu amplo acesso ao público e uma nova sociabilidade que, adaptada ao ambiente tecnológico, envolve interações econômicas, políticas, sociais e culturais ${ }^{14}$. Para Castells ${ }^{14}$, as comunidades virtuais não são opostas às comunidades físicas, mas são pautadas por outras leis, com recursos e intercâmbios distintos.

É nesse sentido que a ascensão da internet e das redes sociais tornou mais visível o processo em que se passou de uma "sociedade dos meios" para uma "sociedade midiatizada", na qual os receptores são ativos no processo de comunicação ${ }^{15}$. Hjarvard ${ }^{16}$ explicita que os meios de comunicação moldaram novos padrões de interação e a própria mídia se confunde com outros processos sociais, resultando na virtualização da interação social. A sociedade contemporânea, nesse contexto, está permeada pela mídia de tal maneira que ela não pode mais ser considerada como algo separado das instituições culturais e sociais ${ }^{16}$.

Seu desenvolvimento inaugura uma nova dinâmica na vida social, já que possibilita, de forma democrática e participativa, a inclusão de usuários na construção da própria rede, aperfeiçoando as interações e as comunidades virtuais, permitindo que atividades antes relegadas apenas a especialistas se tornassem disponíveis para qualquer cidadão. Mas é Lévy ${ }^{13}$ quem alerta que uma das características relevantes da interatividade propiciada pela cibercultura está correlacionada à descentralização dos discursos e do conhecimento. Em certo sentido, o cenário coletivo de produção e propagação de conteúdo recrudesce a chamada crise informacional ligada à qualidade daquilo que é disseminado.

Ferrari ${ }^{17}$ alerta que as alterações promovidas pela internet, como a ampliação das formas de conexão entre indivíduos e, entre indivíduos e grupos, rompendo a horizontalidade da comunicação dos meios tradicionais que se organizavam a partir da relação entre um emissor e muitos receptores, tornou-se o fundamento da crise informacional. Assim, para o autor: "a internet proporciona, em primeiro lugar, a multiplicidade e heterogeneidade das conexões. Cada ponto da rede pode realizar conexões infinitas com múltiplos pontos descentralizados, um rizoma geolocalizável de ocupação de espaços, que estão em constante movimento, pois vivemos um presente 'tagueado', ou seja, um tempo que pode ser resgatado a qualquer minuto por bancos de dados, mas que não se torna desejado, pois a presentificação se impõe sobre a memória. Como o vivenciar é líquido e, no minuto seguinte, estamos vivenciando outra postagem, o tempo necessário para o cérebro verificar a veracidade do fato narrado fica prejudicado, pois na maioria das vezes, só para citar um exemplo, os consumidores compartilham a informação apenas pelo título, sem se dar o trabalho de ler o texto completo ou mesmo verificar a fonte de informação".

Diante da avalanche de conteúdos nem sempre confiáveis disseminados no espaço virtual, o termo desinformação retornou ao centro do debate. Apesar de se tratar de um fenômeno antigo, a desinformação alcançou acentuada proporção em função do surgimento das redes sociais. No intuito de tipificar o conceito, inúmeros pesquisadores revisitaram definições sobre o termo. Wardle e Derakhshan ${ }^{18}$ apresentaram um 
quadro conceitual nomeado de "Information Disorder", com o intuito de estabelecer uma distinção sobre o que eles nomearam de conteúdos de desinformação.

Baseados nas dimensões dano e falsidade, os autore ${ }^{18}$ contextualizaram as diferenças em três categorias: "mis-information", ou informação incorreta, mensagem falsa que comporta conteúdo enganoso, mas sem intenção de causar dano; "mal-information", ou má informação, constituída com a matéria-prima da realidade, mas fruto de vazamento, assédios e discursos de ódio, usadas com a finalidade de prejudicar e, por fim, "dis-information" ou desinformação, informações falsas produzidas com vistas a causar dano seja para um indivíduo, grupo social, seja organização ou país.

Pinheiro e Brito ${ }^{19}$, ao descreverem o conceito de desinformação, também partiram de três tipologias: ausência de informação, informação manipulada e engano proposital. A ausência de informação está associada ao estágio de carência de cultura, de total ignorância e precariedade informacional devido ao total desconhecimento de determinado tema. Já a manipulação da informação, segundo os autores ${ }^{19}$, traz "uma relação com o fornecimento de produtos informacionais de baixo nível cultural, cuja consequência direta seria a imbecilização de setores sociais". Nesse caso,a desinformação teria como propósito a alienação da população, com o intuito de manter projetos de dominação política, ideológica ou cultural. O engano proposital, por sua vez, assume o mesmo sentido proposto por Wardle e Derakhshan ${ }^{18}$, no qual as informações circulam com o propósito de enganar alguém, ou seja, trata-se de um ato deliberado para induzir ao erro.

A ampliação do fenômeno da desinformação encontra-se imbricada com o crescimento exacerbado das fake news que, amparadas pelas redes sociais, tais como Facebook, Twitter e WhatsApp contribuem significativamente para que conteúdos falsos se espalhem com rapidez e tenham longo alcance. A ubiquidade que a internet oferece torna o fenômeno cada vez mais recorrente para diferentes propósitos. A avalanche de opiniões, crenças e valores propagados nos espaços virtuais exige do leitor maior seletividade, sob o risco de consumir conteúdo pouco crível.

Delmazo e Valente 4 indicam que existe uma distância entre a partilha dos links e a sua leitura. No âmbito do compartilhamento de conteúdo, os autores citam o estudo divulgado pela Universidade de Columbia e o Instituto Nacional Francês que aponta que 59\% dos links partilhados nas redes sociais não são de fato clicados. Assim, "uma manchete atraente - que normalmente fica explícita na URL do link - já seria suficiente para garantir engajamento. Mesmo quando os links são clicados, poucos leitores vão passar dos primeiros parágrafos, o que facilita ainda mais o trabalho de elaboração de uma notícia falsa”. Na mesma linha, Conroy, Rubin e Chen²0 alegam que a inserção de links nem sempre confiáveis, usados com a finalidade de atestar a veracidade dos discursos, dificulta a identificação de fake news em textos publicados nas plataformas digitais.

Já os autores Bakir e McStay ${ }^{21}$ chamam a atenção para os investimentos políticos e econômicos na produção de fake news que reajam frente ao comportamento emocional de um grupo inserido nas redes sociais. As emoções são empregadas para despertar a atenção e o tempo de visualização, convertendo-se em receita de publicidade. Na onda da desinformação, é preciso também destacar que um número crescente de indivíduos se mantém suscetível às informações falsas, em função das bolhas e redes pessoais que propiciam a circulação das fake news. Neste sentido, as tecnologias digitais se convertem em instrumentos de propaganda que contribuem para direcionar conteúdos de acordo com o perfil dos usuários.

O resultado das relações homofílicas facilitada pela reciprocidade trazida pela tecnologia acabam por promover um espaço virtual segmentado e alinhado às crenças e opiniões dos usuários. A adesão ligada ao ato de pesquisar, compartilhar ou curtir as mensagens, concomitante às ações dos robôs de plataformas digitais, possui papel relevante na propagação de fake news. A presença de robôs e atores muito engajados, segundo Shahe Kumar (2018 apud ${ }^{22}$ ), contribuem para criar falsas percepções de consenso, impulsionando um circuito de informações não verificadas.

Para além da revolução tecnológica, fatores como a descrença da população nas instituições tradicionais (mídias, política, justiça, Estado) é tida como o cenário que estimula o agravamento do problema. As 
redes sociais, em especial o WhatsApp, permitem a circulação e o compartilhamento de informações em grupos ancorados em um circuito fechado de confiança e crédito, seja amigos, colegas, familiares ou mesmo pessoas que pertencem ao mesmo círculo social. Assim, as pessoas têm preferido acreditar mais em quem conhecem do que nas instituições ${ }^{23}$.

Entre inúmeras informações falsas que circulam no ambiente virtual, deve-se destacar a fake news sobre a eficácia da vacinação.

\section{Entre a ciência e a desinformação: desmistificando as 10 fake news sobre vacinação}

A vacinação e suas campanhas constituem importantes memórias de políticas públicas de imunização. Abordar este tema é transitar e dialogar com aspectos políticos, sociais, econômicos, culturais, religiosos e, mais recentemente, no emaranhado da pós-verdade. Os meios de comunicação estiveram sempre presentes com inúmeras possibilidades de representações e chamadas às campanhas vacinais por todo o país, lado a lado das estratégias inicialmente compulsórias, seguidas de imagens aterrorizantes da não vacinação, para então, caminharem em conjunto com a adesão populacional. Mas, como traçar o caminho que flerta abertamente com um movimento em torno da negação à vacinação?

Foi na Inglaterra em 1796, que Edward Jenner sistematizou seus conhecimentos empíricos e criou uma vacina capaz de prevenir a varíola, a partir da pústula formada pelo vírus vaccínia nas tetas das vacas ${ }^{24}$. Passados mais de 180 anos, a primeira doença combatida por uma vacina foi também aquela, que passou a ser erradicada por meio de programas vacinais e a Organização Mundial da Saúde (OMS) considerou-a mundialmente extirpada em $1980^{25}$. Contudo, o Brasil foi o último país das Américas a erradicar a varíola, com registro de última notificação em $1972^{25}$. Mas os primórdios da vacinação em território nacional foram polêmicos e turbulentos, como apontado anteriormente pela emblemática manifestação nomeada Revolta da Vacina que, para além da recusa da vacinação, expunha uma oposição aos programas de higienização do espaço urbano, preconizados por Oswaldo Cruz, na época Diretor Geral da Saúde Pública ${ }^{24}$.

Em 1973, por determinação do Ministério da Saúde, o Programa Nacional de Imunizações (PNI) foi criado para coordenar as ações de imunização, e procura garantir a aplicação de doses dentro do calendário nacional de vacinação, com percentuais superiores a 90\% para quase todos os imunobiológicos distribuídos na rede pública nas últimas décadas ${ }^{26}$, gerando resultados importantes como a erradicação da varíola, a interrupção da transmissão da poliomielite, a eliminação do sarampo autóctone, e, desde 2010, o Brasil mostra-se livre de casos de rubéola. Atualmente, o Sistema Único de Saúde (SUS) oferece, por meio do PNI, 44 tipos de imunobiológicos, sendo 27 vacinas, 13 soros heterólogos (imunoglobulinas animais) e 4 soros homólogos (imunoglobulinas humanas) ${ }^{27}$.

Desta maneira, seu desenvolvimento foi parte decisiva para a construção da história da saúde pública do país, pois suas contribuições nacionais foram grandiosas, como: operacionalização de grandes mobilizações para vacinação, capacitação dos profissionais de saúde que atuam no setor público, avanços na ciência e tecnologia, valorização do cartão de vacinas e da história individual de saúde, olhar diferenciado para grupos mais vulneráveis, entre outras. Também, houve avanços nos processos comunicacionais e midiáticos para a questão, pois o marketing para as campanhas, evocou heróis nacionais, explorou a diversidade ética, convocou a responsabilidade e o compromisso de vacinar, com linguajar simples que atinge diretamente o público alvo de cada vacinação agendada ${ }^{28}$.

Estes avanços demonstraram não somente os benefícios, mas também certa percepção de riscos da vacinação. O alerta adveio da alteração do cenário de imunização no Brasil, mostrando queda a partir de 2014. Em 2013-2015, registraram-se 1.310 casos de sarampo nos estados do Ceará e de Pernambuco, com declínio de 10 a 20 percentuais das coberturas vacinais a partir de $2016^{26}$. Roraima e Amazonas, com mais de 1.500 casos confirmados, foram consequências diretas da diminuição das coberturas vacinais, em 
2018 ${ }^{29}$. Também a imunização contra a pólio foi a menor dos últimos 12 anos $(84,4 \%)$ em 2016. E mesmo com redução de 23,6\% de casos confirmados de sarampo no país, entre o período de agosto a novembro de 2019, foram notificados 32.518 casos suspeitos de sarampo, com 13,3\% (4.323 casos) confirmados ${ }^{30}$.

Contudo, mesmo reconhecida como uma das medidas de saúde pública mais bem sucedidas, a vacinação é percebida como insegura e desnecessária por um número crescente de pessoas. Os movimentos antivacinação relacionam-se com taxas mais baixas de aceitação de vacina e com aumento de surtos e epidemias de doenças evitáveis, fortalecidos pelo aumento de informações de saúde incorretas compartilhadas especialmente na internet $^{31}$. A hesitação vacinal mostra-se como presente preocupação de pesquisadores em países europeus, asiáticos, africanos e americanos ${ }^{31-33}$. No Brasil, há poucos estudos sobre esta questão ${ }^{29}$, porém a hesitação vacinal tem se mostrado cada vez mais presente ${ }^{29,31}$.

O termo hesitação vacinal refere-se ao atraso na aceitação ou recusa de vacinas, apesar da disponibilidade de serviços de vacinação, por várias razões, a saber: desacreditar que as vacinas funcionam e são eficazes; acreditar que as vacinas não são necessárias; pais ou responsáveis deixarem de permitir a imunização das crianças sob suas responsabilidades; hesitação em relação a novas vacinas. Diferentes fatores influenciam a questão, sendo considerado um fenômeno complexo, de contexto específico e que varia no tempo, nos lugares e com vacinas peculiares, sobretudo em diferentes países.

Em 2012, a OMS criou um grupo especial para caracterizar, discutir e estabelecer estratégias para conduzir pontos relacionados à recusa vacinal: Strategic Advisory Group of Experts (SAGE). Além de monitorar este assunto, é foco deste grupo desenvolver intervenções comunicativas de enfrentamento das falhas nesta confiança, a fim de evitar consequências à saúde pública, procurando identificar relevantes fatores causais e desenvolver estratégias adaptadas para enfrentá-los ${ }^{26,32}$.

A preocupação com a segurança e a necessidade da aplicação das vacinas é mundial e não recente, surgiu logo após a sua introdução contra a varíola no fim do século XVIII, no Reino Unido, e permaneceu no tempo. Nos Estados Unidos, brigas judiciais contra a vacinação obrigatória foram notórias nos anos 1920. Apesar disso, em países de alta renda, as décadas de 1950-1960 foram consideradas como "era de ouro da aceitação vacinal" com a introdução da vacinação universal contra a poliomielite e sarampo-caxumbarubéola, resultando no declínio expressivo dessas doenças ${ }^{26,31}$.

Todavia, os argumentos e as crenças dos grupos antivacinas não sofreram grandes alterações nos dois últimos séculos. Sendo principalmente religiosas e filosóficas, as transformações aconteceram com a capacidade de multiplicação e disseminação da informação que ganhou velocidade e eficácia nas últimas décadas ${ }^{31}$.

Posto isso, a narrativa empregada nas fake news intituladas "10 razões pelas quais você não deveria vacinar seus filhos", Figura 1, incorre em grave e preocupante problema de saúde pública, conforme discutido neste artigo. 
10 Razões Pelas Quais Você NÃO Deveria Vacinar Seus Filhos

1) As vacinas não funcionam.

2) As vacinas nunca foram comprovadamente seguras ou eficazes.

3) A primeira vacina foi um completo fracasso, a qual a indústria tentou

encobrir.

4) As vacinas são altamente lucrativas para as empresas farmacêuticas , as

quais não podem ser responsabilizadas por danos.

5) Todas as vacinas contêm aditivos químicos mortais

6) As crianças não vacinadas são geralmente mais saudáveis.

7) As vacinas causam doenças incuráveis ao longo da vida em algumas

crianças.

8) As vacinas matam crianças e adultos.

9) As companhias de vacinas não podem ser processadas se você ou o seu

filho forem prejudicados pelas vacinas.

10) A exposição natural à doença é a melhor vacina

Figura 1 - Lista com 10 fake news sobre vacinação

Fonte: Página do Facebook Pensadores contra o sistema (2015) ${ }^{\mathrm{vi}}$.

Para realizar a investigação da lista com as 10 fake news sobre vacinação, recorreu-se à pesquisa bibliográfica. Conforme esclarece Boccato35, “a pesquisa bibliográfica busca a resolução de um problema (hipótese) por meio de referenciais teóricos publicados, analisando e discutindo as várias contribuições científicas. Esse tipo de pesquisa trará subsídios para o conhecimento sobre o que foi pesquisado, como e sob que enfoque e/ou perspectivas foi tratado o assunto apresentado na literatura científica”.

Durante o percurso de coleta e análise de dados, a pesquisa bibliográfica se estruturou a partir de três etapas. Na primeira etapa, partiu-se em busca de palavras-chave usadas para localização das referências sobre o tema, em sites de pesquisa científica como SciELO, periódicos (Portal da Capes), Science Research Library e Fundação Oswaldo Cruz (Fiocruz) (foi realizada no Portal da Fundação Fiocruz, site https:// portal.fiocruz.br/ e na revista Reciis, v. 12, n. 1, de 2018, por exemplo). Concomitante, como instrumento de busca, elegeram-se nove palavras-chave relacionadas ao objeto da pesquisa: programas de imunização, políticas de imunização, produção de vacinas, imunológicos, calendário de vacinas, movimento antivacina, campanha de vacinação, cobertura vacinal e recusa de vacinação. Para seleção das palavras-chave foi utilizado o vocabulário estruturado multilíngue DeCS Descritores em Ciência da Saúde ${ }^{\text {vii }}$, que serve como unificador na indexação de artigos de revistas cientificas, livros, Anais de Congresso, relatórios médicos e outros tipos de materiais. A palavra vacinação foi eleita como parâmetro de busca no portal do DeCS, cuja pesquisa resultou em nove descritores relacionados ao tema.

De posse do conjunto de referências, foi realizada uma pré-leitura que eliminou obras que se distanciavam do objetivo do estudo. Por fim, na última etapa foi realizada uma leitura crítica, em profundidade, para separar resultados publicados sobre a vacinação que confrontavam com os argumentos apresentados nas “10 razões pelas quais você não deveria vacinar seu filho". Com o objetivo de confrontar as justificativas em torno da campanha antivacinação, buscou-se um agrupamento por semelhança, em que os dez argumentos foram reunidos em quatro categorias. Assim, as fake news foram reunidas pela semelhança de conteúdo, sendo elas: as vacinas não funcionam; as vacinas beneficiam as indústrias farmacêuticas; as vacinas causam morte ou algum dano aos usuários e não vacinar traz maior imunização aos indivíduos. O Quadro 1 apresenta a distribuição das fake news por categoria:

vi Disponível em: https://www.facebook.com/pensadorescontraosistema/posts/1644903315840284/. Acesso em: 2019 nov. 10. 
Quadro 1 - Distribuição das fake news por categoria

\begin{tabular}{|l|l|l|l|}
\hline $\begin{array}{l}\text { As vacinas não } \\
\text { funcionam }\end{array}$ & $\begin{array}{l}\text { As vacinas causam } \\
\text { morte ou trazem } \\
\text { algum dano aos } \\
\text { usuários }\end{array}$ & $\begin{array}{l}\text { As vacinas } \\
\text { beneficiam } \\
\text { as indústrias } \\
\text { farmacêuticas }\end{array}$ & $\begin{array}{l}\text { Não vacinar permite } \\
\text { maior imunização aos } \\
\text { indivíduos }\end{array}$ \\
\hline $\begin{array}{l}\text { 1) As vacinas não } \\
\text { funcionam }\end{array}$ & $\begin{array}{l}\text { 5) Todas as vacinas } \\
\text { possuem aditivos } \\
\text { químicos mortais }\end{array}$ & $\begin{array}{l}\text { 4) As vacinas são } \\
\text { altamente lucrativas } \\
\text { para as indústrias } \\
\text { farmacêuticas }\end{array}$ & $\begin{array}{l}\text { 6) As crianças não } \\
\text { vacinadas geralmente } \\
\text { são mais saudáveis }\end{array}$ \\
\hline $\begin{array}{l}\text { 2) As vacinas } \\
\text { nunca foram } \\
\text { comprovadamente } \\
\text { seguras e eficazes }\end{array}$ & $\begin{array}{l}\text { 7) As vacinas causam } \\
\text { doenças incuráveis } \\
\text { ao longo da vida em } \\
\text { algumas crianças }\end{array}$ & $\begin{array}{l}\text { 9) As companhias de } \\
\text { vacinas não podem ser } \\
\text { processadas se você } \\
\text { ou seu filho forem } \\
\text { prejudicados pela } \\
\text { vacina }\end{array}$ & $\begin{array}{l}\text { à doença é a melhor } \\
\text { vacina }\end{array}$ \\
\hline $\begin{array}{l}\text { 3) A primeira vacina } \\
\text { foi um completo } \\
\text { fracasso }\end{array}$ & $\begin{array}{l}\text { 8) As vacinas matam } \\
\text { crianças e adultos }\end{array}$ & & \\
\hline
\end{tabular}

Fonte: Os autores (2019).

Para inferência dos resultados, a pesquisa se apoiou no desenvolvimento de uma estrutura descritiva e analítica que, com base no material levantado, seguiu uma linha de contraposição aos argumentos defendidos pelas fake news. Aqueles que trazem 'as vacinas não funcionam', alegando que não são comprovadamente seguras e eficazes, podem ser transparentemente rebatidos, diante da erradicação mundial da varíola, da eliminação da poliomielite, da transmissão da rubéola, entre outras doenças já mencionadas no artigo. Os rumores também versam sobre as vacinas relacionarem-se com "efeitos adversos". Porém, elas são rigorosamente testadas e monitoradas pelos seus fabricantes e pelos sistemas de saúde dos países onde são aplicadas, associando-a entre outras justificativas ao completo fracasso da primeira vacina.

Esse fato foi registrado em 1955 por ocasião da imunização contra a poliomielite, como falha no processo de sua fabricação baseada em vírus inativados. Outros acontecimentos foram registrados com a composição das vacinas BCG (Bacillus Calmette-Guérin), tríplice viral (sarampo, caxumba e rubéola), rotavírus, poliomielite oral e pertussis celular. E diante disso, muitos esforços foram investidos para garantir maior segurança na fabricação e uso de vacinas, para solucionarem decisivamente os feitos mencionados. Também a vacina contra a coqueluche sofreu alterações para substituir a vacina pertussis celular, relacionada a eventos adversos graves na década de $1970^{36}$.

No entanto, apesar do impacto na redução de casos e mortes pelas doenças imunopreveníveis, movimentos anti-vaxx mostram-se cada vez mais presentes e convincentes, utilizando-se de informações falsas com alegações de apresentarem base científica, questionando a eficácia e segurança de diversas vacinas ${ }^{37}$. Um acontecimento marcante foi o estudo publicado em uma das mais influentes revistas médicas, a Lancet, em 1998, do ex-médico pesquisador Andrew Wakefield, afirmando que houve manipulações de dados, omissões de responsabilidade e desvios técnicos, ao disseminar o medo da vacina tríplice viral, ao associá-la com o surgimento de distúrbios gastrointestinais acompanhados de prejuízos no desenvolvimento mental semelhante ao autismo em 12 crianças da Inglaterra após receberem-na.

Mesmo, anos mais tarde, com o artigo anulado, pois não estabelecia uma relação causal (em 2010, a licença médica de Walkefield foi caçada e, a partir disso, a Lancet anulou o artigo; porém o paper ainda pode ser lido online, com a exibição em vermelho, por todo o texto, da palavra retracted) o estrago estava 
feito, a proporção de crianças vacinadas caiu 80\% na Grã-Bretanha em 2003, e em 2008 o sarampo voltou a apresentar-se como doença endêmica na Inglaterra e no País de Gales ${ }^{38}$.

Os "efeitos adversos" são justificados pelo fato de as vacinas possuírem aditivos químicos e mortais, causarem doenças incuráveis ao longo da vida em algumas crianças, podendo inclusive levar à 'morte'. Neste caso, vale ressaltar que somente após aprovação de órgãos reguladores específicos com estudos clínicos criteriosos, dispendiosos e lentos, o licenciamento e a comercialização das vacinas acontece. O passo seguinte à comercialização é o apontamento de eventos adversos não registrados nas fases anteriores, denominados eventos adversos pós-vacinação (EAPV). A partir de 1991, a Organização Mundial da Saúde (OMS) recomendou a vigilância de EAPV, sendo estruturado em 1992, o Sistema Nacional de Vigilância dos Eventos Adversos Pós-Vacinação (VEAPV) no Brasili3 ${ }^{34}$. Além disso, o Instituto Nacional de Controle de Qualidade em Saúde (INCQS) em conjunto com o Sistema Nacional de Vigilância Sanitária (SNVS) atestam e garantem a qualidade dos imunobiológicos distribuídos, possuindo índices de rejeição menores que $1 \%{ }^{36}$.

Distorções e exageros amparam discussões sobrevacinação, com estatísticas confusas entretemporalidade e causalidade pelas limitações do sistema de notificação de eventos adversos, vinculando vacinação aos óbitos, como no caso de 1999 sobre imunológicos da hepatite B. Também houve a questão do mercúrio (contido no timerosal, para evitar contaminação por bactérias ou fungos), nas vacinas dos Estados Unidos, referenciado como causa de várias doenças, em particular o autismo. Mesmo com base factual frágil, pois o composto era utilizado como conservante, entidades americanas recomendaram a retirada do mercúrio das vacinas, devido à apreensão pública com a questão. Porém, vários estudos conduzidos por setores da saúde não consubstanciavam efeitos adversos em função deste uso, e nenhum o associava causalmente com o autismo. O Thimerosal foi retirado das preparações em 2001 e, ainda assim, a identificação de novos casos de autismo se manteve em crescimento ${ }^{39}$. Estreitamentos entre poliomielite e câncer, vacinação de lactentes e asma, vacina contra rotavírus e invaginação intestinal, imunização e diabetes, entre outras, geravam ansiedade e estendiam-se pela mídia, sendo todas elas contestadas ${ }^{40}$.

Há também argumentos facciosos sobre os "ganhos das indústrias farmacêuticas" e sua 'total irresponsabilidade' diante dos efeitos adversos das vacinas. Os litígios, sobretudo os estadunidenses, tornaram-se uma indústria rentável, no final da década de 1970 e início da de 1980, e advogados pouco compromissados com a ética e a saúde pública procuravam possíveis vítimas, estimulando-as a moverem processos legais, que faziam com que produtores de vacinas retirassem seus produtos do mercado, atrasando as campanhas vacinais, chegando a ponto da criação de uma lei denominada National Child hood Vaccine Injury Act para tentar aliviar fabricantes de imunobiológicos de processos judiciais ${ }^{41}$. Afirmações da lista de fake news do movimento anti-vaxx alertando sobre o fato das empresas farmacêuticas serem altamente lucrativas, as quais não poderiam ser responsabilizadas por danos e não poderiam ser processadas caso alguém fosse prejudicado pelas vacinas parecem infundadas. No caso brasileiro, ressalta-se que o Complexo Tecnológico de Vacinas do Instituto de Tecnologia em Imunobiológicos (Bio-Manguinhos/Fiocruz) é que garante a autossuficiência em vacinas essenciais para o calendário básico de imunização do Ministério da Saúde.

Como integrante da Fundação Oswaldo Cruz (Fiocruz), o mencionado instituto é responsável pela produção das vacinas para DTP e Hib, febre amarela, Haemo philus influenzae tipo B (Hib), meningite A e C, pneumocócica 10-valente, poliomielite oral (VOP), poliomielite inativada (VIP), rotavírus humano, tríplice viral e tetravalente viral. A Fiocruz investe desde 25 de maio de 1900 na busca do conhecimento científico e tecnológico, sendo considerada a mais destacada instituição de ciência e tecnologia em saúde da América Latina. Parece inconsistente afirmar que a instituição, cuja missão é promover saúde e desenvolvimento social, esteja aliada essencialmente à prática financeira.

Por fim, as fake news que alertavam 'que não vacinar incide em maior imunização aos indivíduos' foi objeto de pesquisa qualitativa realizada entre grupos de pais e/ou responsáveis designados como 
vacinadores, vacinadores seletivos e não vacinadores. Aqueles que tinham o ato de vacinar como um dever e responsabilidade, o faziam sem questionamentos. Os seletivos vivenciavam indecisão de vacinar ou adiar a vacinação, tornando o ato particularizado diante do extenso cronograma do PNI. Para os que a negavam, houve predominância de um olhar mais naturalista, com menor intervenção médico-hospitalar e mais autonomia parental sobre o cuidado infantil e suas normatizações.

Infere-se daí que pais e/ou responsáveis não vacinadores enquadram as crianças geralmente como saudáveis e a exposição natural à doença poderia ser a melhor vacina, com entendimento que muitas doenças aparentemente demonstram-se controladas e mais leves ${ }^{40,42}$.É preciso esclarecer que a imunização promovida pela vacinação que ocorre respeitando o PNl permite que o organismo se defenda melhor das doenças causadas por alguns tipos de bactérias e vírus. A vacinação não exclui o risco dos indivíduos contraírem doenças, mas o reduz consideravelmente, sendo que os sintomas em caso de contágio são menores. Já a ameaça causada pela falta de vacinação tem sido responsável pelo aumento de mortes que seriam facilmente evitadas com o cumprimento dos protocolos de imunização.

O movimento antivacinação foi incluído pela Organização Mundial de Saúde (OMS) em seu relatório sobre os dez maiores riscos à saúde global em 2019, já que 1,5 milhão de crianças em todo mundo morreram de doenças contraídas comumentemente durante a infância. Por outro lado, estudos realizados em algumas capitais brasileiras comprovam a eficácia e a efetividade da vacinação, demonstrando que a imunização reduziu em até $75,5 \%$ os casos de varicela, reduzindo o índice de mortalidade no país ${ }^{43}$.

António Vaz Carneiro, Ana Isabel Belo, Miguel Gouveia, João Costa e Margarida Borges ${ }^{44}$ constataram, em um levantamento empírico da incidência de doenças preveníveis por vacinação nos Estados Unidos antes e depois da vacinação em massa, considerando o período de 1921 até 2004, que nos últimos dois séculos o desenvolvimento e generalização das vacinas permitiram um avanço notável na luta contra as doenças infecciosas, responsáveis durante milhares de anos pela principal causa de morte da humanidade. Assim, a "exposição natural da doença" pode ser facilmente rebatida, tendo em vista a alta incidência de mortalidade causada pela ausência da vacina.

\section{Considerações finais}

É inegável que a amplitude de informações à qual a sociedade contemporânea está sujeita em face da popularização dos meios digitais facilita o processo de democratização do conhecimento, mas também pode representar um risco social na medida em que coloca em descrédito saberes científicos já fundamentados, testados e verificados. Neste caso, o sistema de vacinação é vítima frequente de uma avalanche de informações inverídicas e danosas para a sociedade.

Foi possível constatar que os argumentos sobre as '10 razões pelas quais você não deveria vacinar seus filhos' se ampara em quatro categorias, que se propagaram inicialmente pelas redes sociais. A democratização do espaço virtual permitiu a ampliação do número de comunidades que atuam, ainda que diante de escassa legitimidade, como consultores da área da saúde, alertando sobre riscos, prevenções, tratamentos alopáticos e/ou naturais para curar ou prevenir doenças. Essa parece ser a tratativa da fake news que indicava a imunização natural como mais efetiva no combate às doenças.

Por outro lado, as informações falsas estão inseridas em um contexto de crise institucional, próprio da modernidade tardia, em que prevalece uma descrença nos sistemas peritos, dos quais a ciência faz parte ${ }^{23}$. Diante das incertezas do mundo moderno, o movimento antivacinação parece ter assumido uma disputa pela narrativa da verdade, apoiada em artigos científicos já contestados, pesquisas com metodologias questionáveis ou até mesmo baseado em relatos pessoais. As redes sociais online parecem estimular o movimento, já que os algoritmos da internet se alimentam de rastros digitais que favorecem a criação de bolhas virtuais cujo propósito é reforçar o consenso de um determinado grupo. 
No caso das fake news sobre vacinação, fatores como a baixa percepção do risco da doença, o receio de eventos adversos pós-vacinação, as dúvidas sobre eficácia e formulação, adicionados à suspeição de interesse mercadológico da indústria farmacêutica estiveram alinhados a tais pressupostos. Não obstante, as distintas abordagens desconsideram os rigorosos padrões de exigência e qualidade atestado em todas as etapas de produção da imunização, desde a fase inicial da pesquisa até a etapa de avaliação de resultados pelas agências reguladoras governamentais, representadas primordialmente pelo Programa Nacional de Imunizações em conjunto com o Instituto Nacional de Controle de Qualidade em Saúde, que atesta e garante a inocuidade e a qualidade dos imunobiológicos distribuídos no país.

\section{Referências}

1. Oxford languages [Internet]. Oxford: Oxford University Press; c2020 [cited 2019 Sept 10]. Available from:https://languages.oup.com/word-of-the-year/.

2. Gooch A. No pós das verdades. Uno [Internet]. 2017 [citado em 202 abr. 19];27:14-15. Disponível em: https://bit.ly/3bGBsWh.

3. Zarzalejos JA. Comunicação, jornalismo e 'fact-checking'. Uno [Internet]. 2017 [citado em 2020 abr. 19];27:11-13. Disponível em: https://bit.ly/3eTCUa1.

4. Delmazo $C$, Valente J. Fake news nas redes sociais online: propagação e reações à desinformação em busca de cliques. Media Jornalismo [Internet]. 2018 [citado em 2020 abr. 19];18(32):155-69. Disponível em: https://bit.ly/2S870g0.

5. Gorgulho G. Crescimento das 'fakenews' influencia agenda pública e requer ações [Internet]. Jornal da Unicamp (Unicamp). 2018 set. 14 [citado em 2019 nov. 11]:Notícias. Disponível em: https://bit. Iy/2W1Pvzm.

6. Sevcenko N. A revolta da vacina. São Paulo: Editora Scipione; 1993.

7. Ponte CF. Vacinação, controle de qualidade e produção de vacinas no Brasil a partir de 1960. História, Ciências, Saúde-Manguinhos [Internet]. 2013 [citado em 2019 nov. 11];10(suppl. 2):619-53. Disponível em: https://bit.ly/3aHG6Ch.

8. Ministério da Saúde (BR), Secretaria de Vigilância em Saúde, Departamento de Vigilância

Epidemiológica. Programa Nacional de Imunizações (PNI): 40 anos. Brasília; O Ministério; 2013 [citado em 2019 nov. 11]. Disponível em: http://bvsms.saude.gov.br/bvs/publicacoes/programa nacional_ imunizacoes pni40.pdf.

9. Vigilância em saúde no Brasil 2003/2019: da criação da Secretaria de Vigilância em Saúde aos dias atuais [Internet]. Brasília, DF: Ministério da Saúde, Secretaria de Vigilância em Saúde; set. 2019 [citado em 2020 mar. 20]. (Boletim Epidemiológico; n. espec.). Disponível em: https://bit.ly/2S9NT5f.

10. European Centre for Disease Prevention and Control. Measles cases and outbreaks [Internet]. 2017 [citado em 2020 mar. 20]. Disponível em: https://www.cdc.gov/measles/cases-outbreaks.html.

11. Centers for Disease Control and Prevention. Comunicable Disease Threats report [Internet]. 2017 [citado em 2020 mar. 20]. Disponível em: https://www.ecdc.europa.eu/en/threats-and-outbreaks/ reports-and-data/weekly-threats.

12. Shimizu NR. Movimento antivacina: a memória funcionando no/pelo (per)curso dos sentidos e dos sujeitos na sociedade urbana. Rev Edicc. 2018 out;5(5):87-97.

13. Lévy P. Cibercultura. São Paulo: Editora 34; 2009.

14. Castells M. A sociedade em rede. São Paulo: Paz e Terra;1999.

15. Neto F. A circulação além das bordas. In: Neto, F, Valdettaro AS, organizadores. mediatización, sociedad y sentido: diálogos entre Brasil y Argentina. Rosario: Universidad Nacional de Rosario; 2010.

16. Hjarvard S. Midiatização: teorizando a mídia como agente de mudança social e cultural. Matrizes [Internet]. 2012 [2020 abr. 26];5(2):53-91. Disponível em: https://www.researchgate.net/ publication/283499425 Midiatizacao teorizando a midia como agente de mudanca social e cultural. 
17. Ferrari P. Fake news, pós-verdade e o consumo de informações. XXVI Encontro Anual Compós; São Paulo: Cásper Líbero; 2017. Disponível em: https://pt.scribd.com/document/382230030/Fake-news-posverdade-e-o-consumo-de-informacoes.

18. Wardle C, Derakhshan H. Information disorder: toward an interdisciplinary framework for research and policy making [Internet]. Estrasburgo: Council of Europe; 2017 [cited 2020 Apr 20]. Council of Europe report DGI(2017) 09. Available from: https://rm.coe.int/information-disorder-toward-an-interdisciplinaryframework-for-re\%20searc/168076277c.

19. Pinheiro MMK, Brito VP. Em busca do significado da desinformação. Data Grama Zero [Internet]. 2014 jan. [2020 abr. 20];15(6):37-58. Disponível em: https://www.brapci.inf.br/index.php/res/v/8068.

20. Chen Y, Conroy NJ, Rubin VL. News in an online world: the need for an "automatic crap detector". P Assoc Inf Sci Tech An [Internet]. 2015 [cited 2020 Apr 20];52(1):1-4. Available from: https://bit. Iy/2VDO6jm.

21. Bakir V, McStay A. Fake news and the economy of emotions: problems, causes, solutions. J Dig Journalism [Internet]. 2018 [cited 2020 Apr 20];6:154-75. Available from: https://doi.org/10.1080/2167 $\underline{0811.2017 .1345645 .}$

22. Recuero R, Gruzd A. Cascatas de fake news políticas: um estudo de caso no Twitter. Galáxia [Internet]. 2019 [citado em 2020 abr. 20];41:31-47. Disponível em: http://www.scielo.br/pdf/gal/n41/1519-311Xgal-41-0031.pdf.

23. Sacramento I. A saúde numa sociedade de verdades. Ver Eletron Comum InfI nov em Saúde [Internet]. 2018 [citado em 2020 abr. 20];12(1):4-8. Disponível em: https://www.reciis.icict.fiocruz.br/index.php/ reciis/article/view/1514.

24. Ministério da Saúde (BR), Secretaria de Vigilância em Saúde, Departamento de Vigilância Epidemiológica. Programa Nacional de Imunizações (PNI): 40 anos. Brasília; O Ministério; 2013. Disponível em: http://bvsms.saude.gov.br/bvs/publicacoes/programa nacional imunizacoes_pni40.pdf.

25. Levi GC, Kallás EG. Varíola, sua prevenção vacinal e ameaça como agente de bioterrorismo. Ver Assoc Méd Bras [Internet]. 2002 [citado em 2020 abr. 20];48(4):357-62. Disponível em: https://bit.ly/2VEz0dj.

26. Succi RCM. Vaccine refusal - what we need tok now. J Pediatria [Internet]. 2018 [citado em 2020 abr. 20];96(6):574-81. Disponível em: https://bit.ly/3eW904K.

27. Ministério da Saúde (BR), Secretaria de Vigilância em Saúde, Departamento de Vigilância das Doenças Transmissíveis. Manual de vigilância epidemiológica de eventos adversos pós-vacinação [Internet]. Brasília; o Ministério; 2014 [acesso em 2020 abr. 20]. Disponível em: https://bit.ly/3eSM1aN.

28. Buss PM, Temporão JG, Carvalheiro JDR, organizadores. Vacinas, soros e imunizações no Brasil. Rio de Janeiro: Editora Fiocruz; 2005.

29. Sato APS. Qual a importância da hesitação vacinal na queda das coberturas vacinais no Brasil?. Rev Saúde Pública [Internet]. 2018 [acesso em 2020 abr. 20];52(96):1-9. Disponível em: http://www.scielo. br/pdf/rsp/v52/pt 0034-8910-rsp-52-87872018052001199.pdf.

30. Vigilância epidemiológica do sarampo no Brasil 2019: Semanas Epidemiológicas 29 a 40 de 2019 [Internet]. Brasília, DF: Ministério da Saúde, Secretaria de Vigilância em Saúde; out. 2019 [citado em 2020 mar. 20]. (Boletim Epidemiológico; n. 50). Disponível em: https://bit.ly/3eWanAq.

31. Dubé E, Vivion M, Mac Donald NE. Vaccine hesitancy, vaccine refusal and the anti-vaccine movement: influence, impact and implications. Expert Rev Vaccines [Internet]. 2015 [cited $2020 \mathrm{Apr}$ 2020];14(1):99-117. Available from: https://bit.ly/2xQqBux.

32. Dubé E, Gagnon D, Nickels E, Jeram S, Schuster M. Mapping vaccine hesitancy - country-specific characteristics of a global phenomenon. Expert Rev Vaccines[Internet]. 2014[cited $2020 \mathrm{Apr}$ 2020];32(49):6649-54. Available from: http://dx.doi.org/10.1016/j.vaccine.2014.09.039.

33. Larson $\mathrm{HJ}$, Jarrett $\mathrm{C}$, Eckersberger E, Smith DMD, Paterson P. Understanding vaccine hesitancy around vaccines and vaccination from a global perspective: asystematic review of published literature, 20072012. Vaccine [Internet]. 2014 [cited 2020 Apr 2020];32(19):2150-59. Available from: https://doi. org/10.1016/j.vaccine.2014.01.081.

34. Olive JK, Hotez PJ, Damania A, Nolan MS. The state of the antivaccine movement in the United States: afocused examination of nonmedical exemptions in states and counties. PLoSMed [Internet]. 2018 [cited 2020 Apr 2020];15(6):e1002578. Available from: https://doi.org/10.1371/journal.pmed.1002578. 
35. Boccato VRC. Metodologia da pesquisa bibliográfica na área odontológica e o artigo científico como forma de comunicação. Ver Odontol Univ Cid São Paulo [Internet]. 2006 [acesso em 2020 abr. 20];18(3):265-74. Disponível em: https://bit.ly/2Sb5xWr.

36. Moraes LRM, Floriano MA, Araujo PS, Castro JT, Santos FAO, Ferreira LCS. Eventos adversos de vacinas e as consequências da não vacinação: uma análise crítica. Rev Saúde Pública [Internet]. 2018 [acesso em 2020 mar. 20];52:40:1-13. Disponível em: http://www.scielo.br/pdf/rsp/v52/0034-8910rsp-S1518-87872018052000384.pdf.

37. Kata A. Anti-vaccine activists, Web 2.0, and the postmodern paradigm: an overview of tactics and tropes used online by the anti-vaccination movement. Vaccine [Internet]. 2011 [cited $2020 \mathrm{Apr}$ 20];30(25):3778-89. Available from: https://doi.org/10.1016/j.vaccine.2011.11.112.

38. Zorzetto R. Manipulação de dados: fraude em estudo sobre vacina reabre discussão acerca das práticas de pesquisa. Pesquisa Fapesp [Internet]. 2011 mar. [citado em 2020 mar. 20];181. Disponível em: https://bit.ly/2Y3vlaO.

39. Silva PRV, Castiel LD, Griep RH. A sociedade de risco midiatizada, o movimento antivacinação e o risco do autismo. Ciên Saúde Coletiva [Internet]. 2015 [acesso em 2020 mar. 20];20(2):607-16. Disponível em: https://bit.ly/3bHO7s6.

40. Martins RM, Maia MLS. Eventos adversos pós-vacinais e resposta social. Hist Ciên Saúde-Manguinhos [Internet]. 2003 [acesso em 2020 mar. 20];10(Suppl. 2):807-25. Disponível em: https://dx.doi. org/10.1590/S0104-59702003000500018.

41. Couto MT, Barbieri CLA. Cuidar e (não) vacinar no contexto de famílias de alta renda e escolaridade em São Paulo, SP, Brasil. Ciênc Saúde Coletiva [Internet]. 2015 [acesso em 2020 mar. 20];20(1):105-14. Disponível em: https://bit.ly/2VGbY68.

42. Barbieri CLA, Couto MT, Aith FMA. A (não) vacinação infantil entre a cultura e a lei: os significados atribuídos por casais de camadas médias de São Paulo, Brasil. Cad Saúde Pública [Internet]. 2017 [acesso em 2020 mar. 20];33(2):1-11. Disponível em: https://dx.doi.org/10.1590/0102-311x00173315.

43. Sarris AB, Macedo Gl, Mancini FP. Liga acadêmica de terapêutica médica e o combate ao movimento antivacinação. In: Resumo do $15^{\circ}$ Encontro Conversando sobre Extensão na UEPG; 2015 Ponta Grossa: Universidade Estadual de Ponta Grossa, 2017. Disponível em: https://bit.ly/2VDhExG.

44. Carneiro AV, Belo AI, Costa J, Borges M. Efectividade clínica e análise económica da vacinação preventiva. Acta Med Port [Internet] 2011 [acesso em 2020 mar. 20];24:565-86. Disponível em:https:// bit.ly/2x8IDsu.

45. Pôrto A, Ponte CF. Vacinas e campanhas: as imagens de uma história a ser contada. Hist Ciênc SaúdeManguinhos [Internet]. 2003 [acesso em 2020 mar. 20];10(Suppl. 2):725-42. Disponível em: https:// dx.doi.org/10.1590/S0104-59702003000500013. 